\title{
Resource availability determines food chain length in Chinese subtropical rivers
}

\author{
Yuyu Wang $\cdot$ Xiewen Xiao $\cdot$ Xiubo Yu $\cdot$ Jun Xu \\ Yongjiu Cai · Guangchun Lei
}

Received: 24 June 2015/Accepted: 17 January 2016/Published online: 3 February 2016

(C) Springer Science+Business Media Dordrecht 2016

\begin{abstract}
Three prevailing hypotheses, namely resource availability, ecosystem size, and disturbance, are often used to explain variations in food chain length (FCL). Rivers vary widely in size, resources, and disturbance dimensions, even within the same catchment, providing an ideal platform to test ecological drivers of FCL in aquatic systems. In this study, we tested how resource availability (indicated by macroinvertebrate biomass), ecosystem size (indicated by basin area), and disturbance (indicated by daily water-level coefficients of variation) affected stable isotope-based estimates of FCL in subtropical rivers in the Province Jiangxi, China. The FCL varied widely among the studied rivers with a mean of 3.09 (range 2.00-3.99). Model-selection results indicated
\end{abstract}

Handling Editor: Piet Spaak.

Electronic supplementary material The online version of this article (doi:10.1007/s10452-016-9567-2) contains supplementary material, which is available to authorized users.

Y. Wang · G. Lei $(\bowtie)$

School of Nature Conservation, Beijing Forestry

University, Beijing, China

e-mail: leiguangchunbjfu@gmail.com;

guangchun8099@gmail.com

X. Xiao - X. Yu

Key Laboratory of Ecosystem Network Observation and Modeling, Institute of Geographic Sciences and Natural Resources Research, Chinese Academy of Sciences, Beijing, China that resource availability could explain $60 \%$ of the observed variation in FCL. The FCL of the studied rivers was positively correlated with fish richness and the total area of fish community $\delta^{13} \mathrm{C}-\delta^{15} \mathrm{~N}$ bi-plot space, thereby indicating that an increase in fish diversity could influence the trophic structure within the food web and lead to a longer FCL. Taken together, our results suggest that resource availability could predict FCL in subtropical rivers and plays a significant role in maintaining longer FCLs by providing more energy to support upper trophic-level fishes.

Keywords Resource availability · Ecosystem size · Disturbance $\cdot$ Food chain length $\cdot$ Stable isotope

\section{Introduction}

Food webs form a central theme within ecology as they represent feeding relationships among community members and are strongly linked to biodiversity

\footnotetext{
J. Xu

Donghu Experimental Station of Lake Ecosystems, State

Key Laboratory of Freshwater Ecology and

Biotechnology, Institute of Hydrobiology, Chinese

Academy of Sciences, Wuhan, China

Y. Cai

State Key Laboratory of Lake Science and Environment Research, Nanjing Institute of Geography and Limnology, Chinese Academy of Sciences, Nanjing, China
} 
and energy flow (Pimm 1982; Post 2002a; Thompson et al. 2012). The number of trophic transfers between basal resources and top predators of a system is the food chain length (FCL), which is a fundamental and measurable property of food webs (Sabo et al. 2009; Post 2002a). FCL influences how a food web responds to biotic and abiotic factors, for instance, by affecting how trophic cascades may proceed and their outcomes (Carpenter and Kitchell 1993; Xu et al. 2014; Jacob et al. 2015), productivity (Pauly et al. 1998), and toxin bioaccumulation (Cabana and Rasmussen 1994). Understanding the factors that determine FCL through exploring natural variations in FCL across ecosystems is important to improve our understanding of how ecosystems respond to environmental conditions.

Three main hypotheses (i.e., resource availability, ecosystem size, and dynamic stability) have received the most research attention (Sabo et al. 2009). The "resource availability" hypothesis assumes that FCL depends on the amount of energy available to the upper trophic levels because limited efficiency in trophic conversion inevitably diminishes the energy available at higher trophic levels (Pimm 1982; Schoener 1989). The "ecosystem size" hypothesis speculates that FCL increases with increasing ecosystem size because larger ecosystems generally display greater habitat availability and suitability for top predators (Post et al. 2000; Post 2002a; Post and Takimoto 2007). Finally, the "dynamic stability" hypothesis claims that longer food chains take more time to recover from perturbations than shorter food chains and are dynamically unstable because longer food chains are less resilient to perturbations than shorter ones (Pimm and Lawton 1977). Although an increasing number of studies have tested the hypotheses in a variety of natural systems, none of these hypotheses has received universal empirical support, even within particular ecosystem types (Sabo et al. 2009). Few studies have considered all three hypotheses explicitly - many focus only on one or two of these concepts simultaneously (Sabo et al. 2009, 2010).

A recent meta-analysis of 13 empirical studies found that productivity and ecosystem size positively influenced FCL and that disturbance did not significantly shorten food chains (Takimoto and Post 2013). Although productivity generally increases FCL (Thompson and Townsend 2005; Hoeinghaus et al. 2008; Doi 2012), the effects of the magnitude of ecosystem size could positively (Post et al. 2000;
Takimoto et al. 2008; Doi et al. 2009; McHugh et al. 2010; Sabo et al. 2010) or neutrally (Thompson and Townsend 2005; Warfe et al. 2013) influence FCL. Furthermore, the effects of disturbance on FCL are highly variable and could be positive (Calizza et al. 2012), neutral (Walters and Post 2008; Warfe et al. 2013), or even negative (McHugh et al. 2010; Sabo et al. 2010).

Rivers widely varying in size, resource, and disturbance regimes even within a single catchment provide a good platform to test these hypotheses. However, the results of previous studies on rivers are inconsistent. For example, studies on New Zealand streams and North American rivers have indicated that ecosystem size and disturbance best explain across-site patterns in FCL (McHugh et al. 2010; Sabo et al. 2010). In addition, experimental low-flow disturbance was shown to affect the food web structure of the rivers substantially (Walters and Post 2008). By contrast, Calizza et al. (2012) found that the effect of flood disturbance on urban river FCL in Rome varies at different timescales: The increase in mean FCL was short term because of the effect of urbanization on the food web structure. Warfe et al. (2013) reported that resource availability, disturbance, and ecosystem size have no influence on the FCLs of seasonally connected northern Australian rivers. These rivers exhibited a distinct seasonal hydrology. Periodic flooding was proposed to facilitate predatory fish movement, which links isolated food webs and potentially creates a regional food web that could override the local effects of productivity, disturbance, and ecosystem size (Warfe et al. 2013). Therefore, while good progress has been made in understanding how these three hypotheses are important under varying contexts, more work is needed to refine our understanding of when and how each of these factors determines FCL. Given that much of the previous work in this field has been conducted on temperate systems (Thompson and Townsend 2005; Walters and Post 2008; McHugh et al. 2010; Sabo et al. 2010), extension to lower latitudes would broaden our understanding of this topic.

Subtropical rivers are characterized by relatively high annual average temperature (normally greater than $15^{\circ} \mathrm{C}$ ) and marked seasonality in river flow driven by predictable rainfall patterns. Flooding may benefit fish breeding, growth, and survival, in turn influencing FCL and the food web structure, given the importance of fish as intermediate and top consumers 
(Jepsen and Winemiller 2002). It is currently unclear if and how seasonal hydrological variation influences FCL of subtropical rivers.

In this study, we utilized stable isotope ratios of nitrogen and carbon $\left(\delta^{15} \mathrm{~N}\right.$ and $\left.\delta^{13} \mathrm{C}\right)$ taken from tissues from a range of species to determine the trophic position of the species and overall FCL of subtropical rivers at Poyang Lake basin in Province Jiangxi, China. We hypothesize that (1) more productive rivers would have longer food chains, (2) rivers with larger basin areas would have longer food chains, and (3) rivers with more hydrological variations would have shorter food chains.

\section{Materials and methods}

\section{Study sites}

Fish, macroinvertebrates, and river physical attributes were sampled at 16 sites at the tributaries and mainstreams of Fu River, Rao River, Xin River, and Xiu River (Fig. 1) in November 2012. These rivers flow into the Poyang Lake, which is connected to the mid-lower Yangtze River Reach (Huang et al. 2013). We selected sites that encompass a broad range of basin area $\left(9.2-8753 \mathrm{~km}^{2}\right)$, widths $(9-700 \mathrm{~m})$, and mean annual discharge $\left(0.24-310.90 \mathrm{~m}^{3} / \mathrm{s}\right.$ (Supplementary material in Appendix 1). All sites were located 5-10 m away from each hydrological station (Fig. 1), and the elevation of the rivers was between 9 and $113 \mathrm{~m}$ above sea level. Sampling sites at the main channels were set up at the upper, middle, and lower reaches of the rivers. To minimize human impacts, all sampling sites were located far from the outlets of urban areas, farms, and industrial enterprises. The climate of the study area was subtropical $\left(17-17.8{ }^{\circ} \mathrm{C}\right.$ mean annual air temperature), and featured variable seasonal precipitations with heavy rainfall (nearly $48.2 \%$ ) associated with floods from April to June. The dry season in this area began in October and ended in December; during this season, rainfall accounted for less than $10 \%$ of the total rainfall over the whole year.

\section{Characterization of ecosystem size, resource} availability, and disturbance

River catchment area data from the hydrological data of Yangtze Basin, Annual Hydrological Report
People's Republic of China were used to define the ecosystem size of each sampled river. The basin area of each sample site was defined as the area surrounded by waterline from the sample site section to the headwater. Resource availability across sites was characterized based on the biomass of primary consumer macroinvertebrates (McHugh et al. 2010); primary consumers integrate both autochthonous and allochthonous resources and thus provide a suitable prey baseline for estimating higher consumer's diet within river ecosystems. Disturbance was estimated to quantify hydrological regimes across sites by using the coefficients of variation (CVs) of daily water levels at the 16 sample sites in 2011 .

Sample collection and stable isotope analysis

Primary consumer samples $(n=3)$ were collected in December 2012, using a $0.025-\mathrm{m}^{2}$ modified Peterson grab; the samples were pre-sieved in situ at a smaller size fraction $(250 \mu \mathrm{m})$. In the laboratory, the samples were sorted on a white tray, and the animals were preserved in $7 \%$ buffered formalin solution. Specimens were identified to family, blotted dry, and weighed in an electronic balance (precision $0.1 \mathrm{mg}$ ). Mollusca were weighed with their shells. At shallow riparian areas, macroinvertebrates for stable isotope analysis were picked by hand. At deeper areas, a D net was used. Fish were collected by electrofishing for about $300 \mathrm{~m}$ for $20 \mathrm{~min}$ at each site, as the activity range of fish was low during the low-water winter season (the sampling time). All fish samples were identified to the species level in the laboratory. The FCL at each site was estimated following the maximum trophic position $\left(T_{\mathrm{p}}\right)$ convention based on stable nitrogen isotopes in the basal and potential top-level taxa. Tp was estimated as:

$T_{p}=\frac{\delta^{15} \mathrm{~N}_{\text {consumer }}-\delta^{15} \mathrm{~N}_{\text {baseline }}}{3.4}+2$

The value $3.4 \%$ is the average enrichment in $\delta^{15} \mathrm{~N}$ per trophic level (Post 2002b). Despite potential variations in trophic-level enrichment, independent diet-based validations suggest that $3.4 \%$ can yield accurate TP estimates for fishes (Vander Zanden et al. 1997; Rybczynski et al. 2008), which form the core of our dataset. Thus, for our analysis, we assume that $3.4 \%$ is appropriate. The baseline is the average $\delta^{15} \mathrm{~N}$ value of all snails collected at each sample site 


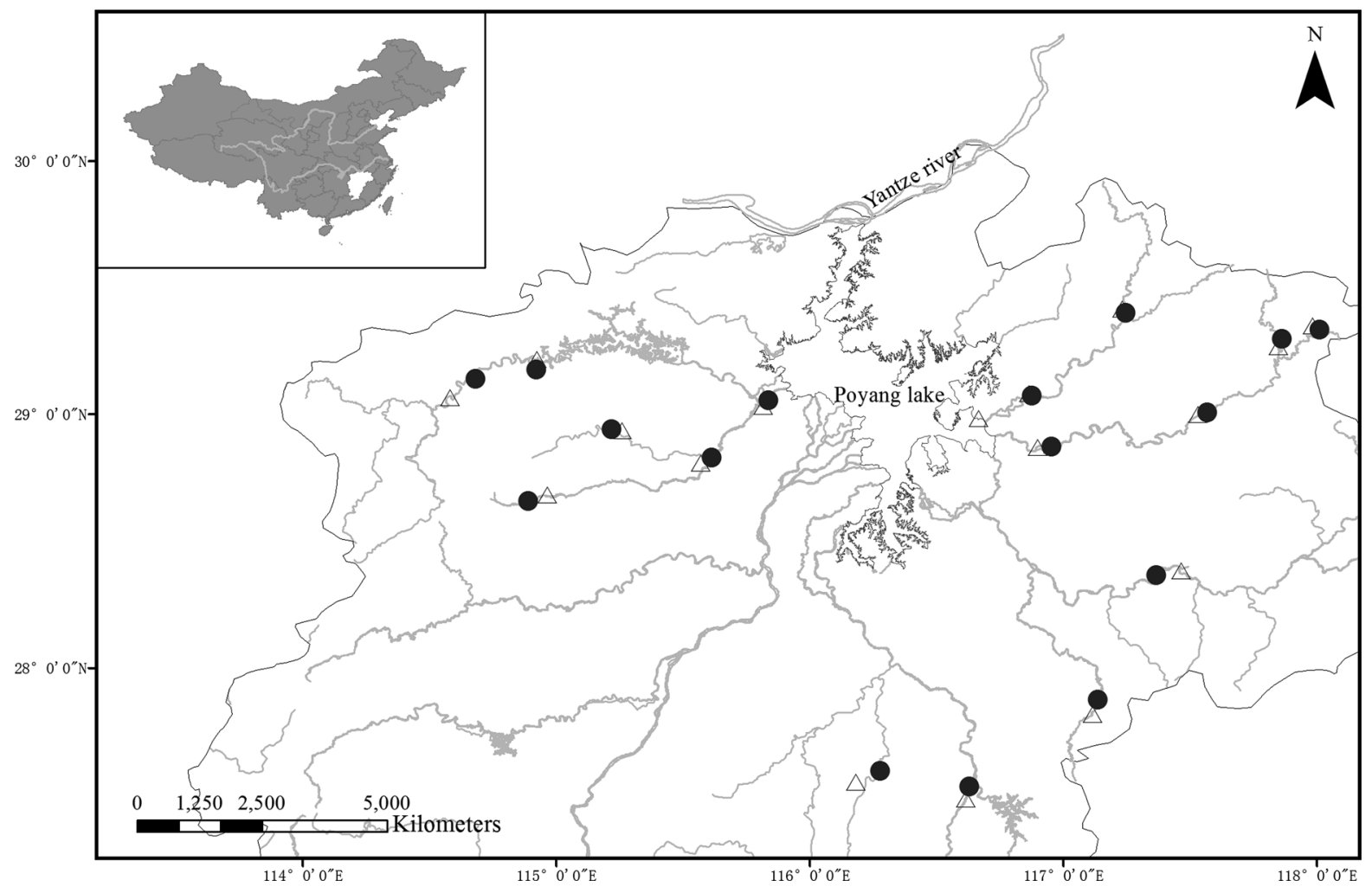

Fig. 1 Map of the study area and sample sites. The study area is indicated by the white region in the inset in the figure. Black circles represent sample sites; triangles represent hydrological stations

( $n=3-10)$ because their isotopic signals are less variable in time as primary consumers (Post 2002b; Wang et al. 2013), where the value 2 is the trophic position of the snail we using to estimate $\delta^{15} \mathrm{~N}$ base (Vander Zanden et al. 1997; Post 2002b).

The snails were kept in distilled water for $24 \mathrm{~h}$, and their shells were removed by cutting their foot muscle using a scalpel for stable isotope analysis. The white dorsal muscle of each fish was removed using a scalpel. All muscle samples were dried at $60{ }^{\circ} \mathrm{C}$ and then ground to fine powder using mortars and pestles. National standards of animal research ethics, including guidelines for animal collection and handling, were followed during sample preparation including animal collection and handling. Stable isotopic analysis was performed on approximately $1 \mathrm{mg}$ (weighed to $1 \mu \mathrm{g}$ using Mettler Toledo MX5 microbalance) of the prepared powder samples using Finnegan MAT 253 (Thermo Scientific, USA) continuous-flow isotope ratio mass spectrometer coupled to a Flash Elemental Analyzer 1112 system (Institute of Geographic Sciences and Natural Resources Research,
Chinese Academy of Sciences). The isotope values were expressed as $\delta^{13} \mathrm{C}$ and $\delta^{15} \mathrm{~N}$ (per thousand percent) in the following equation:

$\delta^{13} \mathrm{C}$ or $\delta^{15} \mathrm{~N}=\left[\left(R_{\text {sample }} / R_{\text {standard }}\right)-1\right] \times 1000$,

where $R={ }^{13} \mathrm{C} /{ }^{12} \mathrm{C}$ or ${ }^{15} \mathrm{~N} /{ }^{14} \mathrm{~N}$.

Reference standards for $\delta^{13} \mathrm{C}$ and $\delta^{15} \mathrm{~N}$ were Pee Dee Belemnite limestone and atmospheric nitrogen, respectively. Based on replicates of laboratory standards (urea), analytical precisions of \pm 0.1 and $\pm 0.3 \%$ were observed for $\delta^{13} \mathrm{C}$ and $\delta^{15} \mathrm{~N}$.

\section{Community-wide metrics}

Community-wide metrics were applied to the isotopic fish data, in accordance with Layman et al. (2007). The $\delta^{13} \mathrm{C}-\delta^{15} \mathrm{~N}$ bi-plot space, in which the taxa were plotted as the niche space, was considered. The total area (TA) was calculated for the entire community as the convex hull area encompassing all 
the fish taxa in the $\delta^{13} \mathrm{C}-\delta^{15} \mathrm{~N}$ bi-plot space. TA represents a measure of the total amount of niche space occupied and is thus a valid proxy of the total extent of trophic niche width within a food web (Layman et al. 2007). The $\delta^{15} \mathrm{~N}$ range (NR), which is the distance between the lowest and highest $\delta^{15} \mathrm{~N}$ values, was considered to reflect the span of fish trophic levels. NR represents the vertical structure within a food web; in general, a larger range of $\delta^{15} \mathrm{~N}$ among consumers suggests more trophic levels (Layman et al. 2007; Perkins et al. 2014). By contrast, the $\delta^{13} \mathrm{C}$ range (CR), which is the distance between the lowest and highest $\delta^{13} \mathrm{C}$ values, was considered representing a measurement of the range of the resources used by the taxa. Increased CR in food webs reveals the presence of multiple basal resources with varying $\delta^{13} \mathrm{C}$ values (Layman et al. 2007). Fish community-wide metrics were analyzed using SIBER Bayesian version (Jackson et al. 2011) provided in the SIAR package ver. 4.2 (Parnell et al. 2008, 2010) in R ver. 3.2.2 software (R Development Core Team 2010).

\section{Data analysis}

The weight of the evidence in support of the three FCL hypotheses was evaluated using an information-theoretic model-selection approach. First, a null model with the three explanatory variables and their two- and three-way interactions (i.e., a total of six variables) was fitted to the data. Second, a backward stepwise technique was employed to select the best fitted regression model. The model with lowest $\mathrm{AIC}_{\mathrm{c}}$ (small sample corrected AIC) was reported as the best fitting one. In addition, AIC weight $\left(\mathrm{AIC}_{\mathrm{w}}\right)$ was used to assess the relative likelihood of each candidate model using the function "dredge" in the MuMIn package (Barton 2012). To evaluate the relative importance to variables for the variations in $\mathrm{FCL}$, the $\mathrm{AIC}_{\mathrm{w}}$ over all of the models with $\Delta \mathrm{AIC}_{\mathrm{c}}$ less than 4 was summed (Burnham and Anderson 2002).

\section{Results}

A total of 25 species of fish ( $n=247)$ (Supplementary material in Appendix 2) and 6 species of snails (i.e., Bellamya aeruginosa, Parafossarulus sinensis, Bithynia fuchsiana, Bithynia misella, Semisulcospira libertina, Parafossarulus eximius, and Radix auricularia) $(n=109)$ were analyzed to estimate FCL. The average FCL was 3.09, ranging from 2.00 (site 2 at Xiu River) to 3.99 (site 3 at Xiu River) across the 16 sampled rivers. A total of 10 different fish species (i.e., carnivores at 2 sites, insectivores at 4 sites, and omnivores at 10 sites) occupied the maximum trophic position across the 16 river food webs (Appendices 2, 3). The algae and organic matter feeder Zacco platypus and insect feeder Opsarilchthys bidens were the most commonly collected fish at the upstream tributaries of the studied rivers. In the middle reach of rivers, where the river channel widens, fish composition became more complex, including herbivorous, carnivorous, and omnivorous species, such as Squaliobarbus curriculus, Culter alburnus, and Carassius auratus. Downstream of the lake inlet, pelagic fish Hemiculter bleekeri and Hemiculter leucisculus were added into the food web (Supplementary material in Appendices 2, 3).

FCL variation was best explained by resource availability (Tables 1,2 ), which showed the lowest $\mathrm{AIC}_{\mathrm{c}}$ and represented $60 \%$ of the model weight. Thus, a significant positive relationship between resource availability and FCL was found $(\mathrm{FCL}=2.775+$ 0.021 [resource availability], $R^{2}=0.431, d f=15$, $p=0.006$ ) (Fig. 2b). Ecosystem size and water-level $\mathrm{CV}$, respectively, accounted for 16 and $13 \%$ of the corresponding model weight (Table 1). Ecosystem size also showed a positive relationship with FCL $\left(\mathrm{FCL}=2.779+6.657 \mathrm{e}^{-5}\right.$ [ecosystem size], $R^{2}=$ 0.329, $d f=15, p=0.020$ ) (Fig. 2a). Water-level $\mathrm{CV}$ revealed no significant relationship with FCL $\left(R^{2}=0.113, d f=15, p=0.202\right.$ ) (Table 1, Fig. 2c). Resource availability positively related to ecosystem size (resource availability $=1.955+0.003$ [ecosystem size], $R^{2}=0.517, F_{1,14}=14.976, p=0.002$ ) and with water-level CV $\left(R^{2}=0.331, F_{1,15}=6.930\right.$, $p=0.020$ ), while ecosystem size positively related to

Table 1 Summary of component models with $\Delta \mathrm{AIC}_{\mathrm{c}} \leq 4$

\begin{tabular}{llll}
\hline Component models & $\mathrm{AIC}_{\mathrm{c}}$ & $\Delta \mathrm{AIC}_{\mathrm{c}}$ & Weight \\
\hline Resource & $\mathbf{1 9 . 1 0}$ & $\mathbf{0 . 0 0}$ & $\mathbf{0 . 6 0}$ \\
Ecosystem & 21.74 & 2.64 & 0.16 \\
Resource, ecosystem & 22.13 & 3.02 & 0.13 \\
$\mathrm{CV}$, resource & 22.67 & 3.57 & 0.10 \\
\hline
\end{tabular}

The best model is indicated in boldface 
Table 2 Averaged coefficients of all variables included in the candidate models with $\Delta \mathrm{AIC}_{\mathrm{c}} \leq 4$ (Table 1) and their importance in FCL

\begin{tabular}{llllcc}
\hline & Estimate & SE & Adjusted SE & $p$ & Importance \\
\hline Intercept & 2.78 & 0.13 & 0.14 & $<0.001$ & $\mathbf{0 . 0 2}$ \\
Resource & $\mathbf{0 . 0 2}$ & $\mathbf{0 . 0 1}$ & $\mathbf{0 . 0 1}$ & 0.24 & 0.84 \\
Ecosystem & $4.75 \mathrm{e}-5$ & $3.64 \mathrm{e}-5$ & $3.89 \mathrm{e}-5$ & 0.84 & 0.10 \\
CV & -1.15 & 5.33 & 5.77 & & 0.29 \\
\hline
\end{tabular}

Significant variables (i.e., $p<0.05)$ are indicated in boldface

water-level CV $\left(R^{2}=0.539, F_{1,15}=16.397, p=\right.$ $0.001)$.

FCL was significantly positively related with fish species richness $\left(R^{2}=0.505, F_{1,13}=13.28, p=\right.$ $0.003)$, TA $\left(R^{2}=0.371, F_{1,13}=7.658, p=0.016\right)$, $\mathrm{NR}\left(R^{2}=0.266, F_{1,13}=4.706, p=0.049\right)$, and CR $\left(R^{2}=0.299, F_{1,13}=5.539, p=0.035\right)$. Among the environmental determinants studied, only resource availability demonstrated a significant positive relationship with fish species richness $\left(R^{2}=0.406\right.$, $F_{1,13}=8.868, p=0.011$ ).

\section{Discussion}

The average FCL of the studied rivers was 3.09, which is shorter than the reported global mean stream FCL but still within the observed range (Vander Zanden and Fetzer 2007). Despite the theoretical and smallscale experimental support for the connections between productivity and FCL (Pimm and Kitching 1987; Jenkins et al. 1992), multiple studies, including several larger-scale field comparisons, have failed to identify productivity alone as a primary driver of increased FCL (Vander Zanden et al. 1999; Post et al. 2000; Sabo et al. 2010). We found that resource availability can explain $60 \%$ of the FCL variation in our studied subtropical rivers, consistent with findings on neotropical (Hoeinghaus et al. 2008) and temperate (Thompson and Townsend 2005) rivers. A previous research on Australian wet-dry tropical rivers used nutrient concentration as a measure of productivity, but the results could not explain the relationship between resource availability and FCL (Warfe et al. 2013). In the present study, we found that resource availability increased as the river basin area increased and that fish species richness was also positively related to resource availability. Resource availability positively related to the water-level $\mathrm{CV}$, indicating that a regime of hydrological variations likely influences patterns in local resource composition.

Three studies revealed positive ecosystem size effects as well as positive productivity effects (Vander Zanden et al. 1999; Thompson and Townsend 2005; Doi et al. 2009), thereby indicating that an increase in ecosystem size lengthens the food chains in system via increasing the availability of total resources. In our study, we also found this relationship between FCL and resource availability. Ecosystem size may increase FCL because greater basal resources are available in larger ecosystems to support a greater biomass and provide adequate energy to support additional trophic levels (Schoener 1989). Positive freshwater fish diversity-basin area and diversitydischarge relationships have been previously established (Wang 1997). Trophic diversity may also be higher in larger ecosystems, thus contributing to longer food chains (Cohen and Newman 1991; Post et al. 2000).

The positive relationship we observed between FCL and fish community NR (Supplementary material in Appendix 4) showed that NR quantifies FCL well, as proven by Perkins et al. (2014). The positive relationship we observed between FCL and fish community CR (Supplementary material in Appendix 4) also indicated that the diversity of basal resources potentially influences FCL. We observed large variations in $\delta^{13} \mathrm{C}$ signatures across both prey and fish predators (Supplementary material in Appendix 2), which suggests that greater diversity of prey resources supports higher trophic levels because $\delta^{13} \mathrm{C}$ provides an indicator of source-consumer interactions (Perkins et al. 2014). The FCL of the rivers in this study was positively related to fish richness and TA, which indicate that as the potential energy available to higher trophic levels increases, addition of new taxa may help 

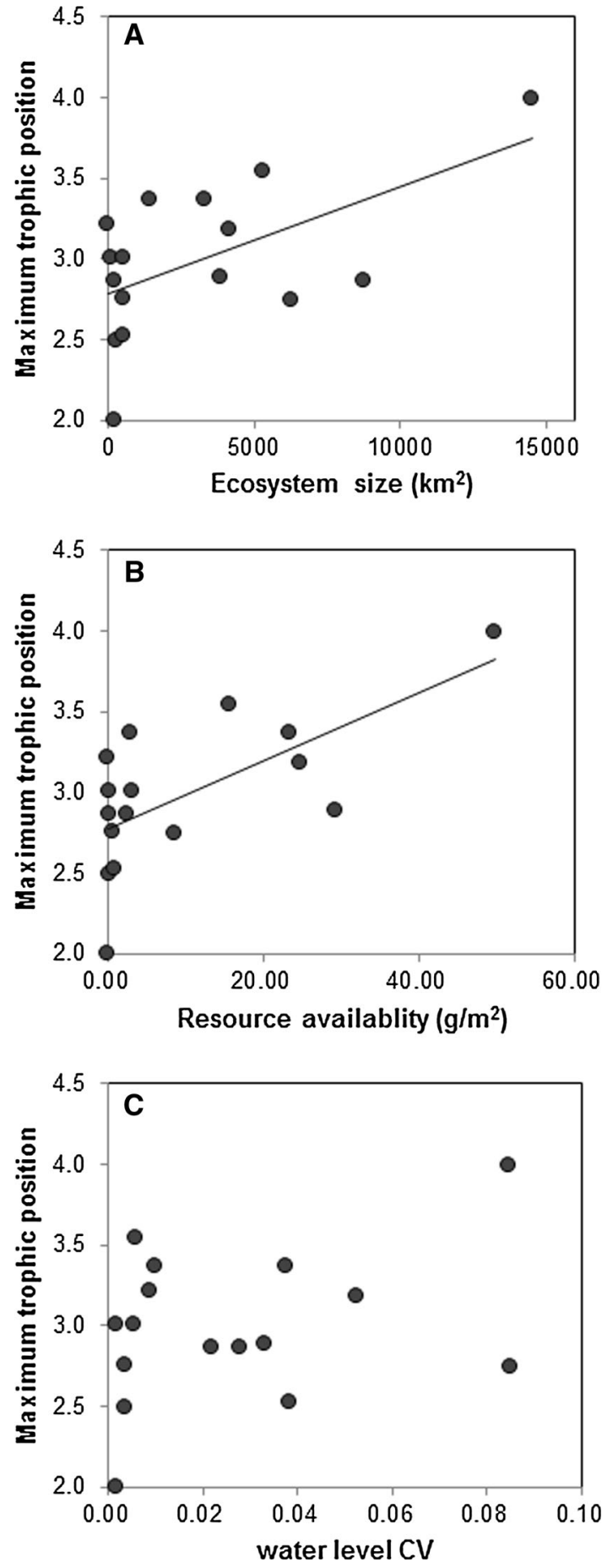

Fig. 2 Relationships among FCL (maximum trophic position), a ecosystem size, $\mathbf{b}$ resource availability and $\mathbf{c}$ disturbance

explain the observed FCL extension (Cohen and Newman 1991; Post and Takimoto 2007), through increases in biodiversity or relative abundance of consumers. The positive relationship between FCL and fish species richness has also been previously observed in lake ecosystem (Vander Zanden et al. 1999). TA estimated the convex hull area for all taxa in a certain community based on their isotopic positions within a $\delta^{13} \mathrm{C}-\delta^{15} \mathrm{~N}$ bi-plot and provides a robust estimate of total trophic diversity (Jackson et al. 2011). Previous study tested the influence of disturbance on FCL and found either neutral or negative effects, with "no effect" as the average result (Takimoto and Post 2013). Although river biota in the subtropical Poyang Lake basin experience dry and wet seasons, as theorized elsewhere (Sabo et al. 2010), the connections between rivers and their tributaries may function as species sources or refuges that could dampen population fluctuations and maintain greater FCL stability.

Several sources of bias could have affected our results: First, while we chose snails as stable isotope baseline to calculate FCL, subtropical rivers present multiple potential resources that can contribute substantially to higher trophic-level consumers. A study in Rao River found that in the dry season, aquatic plants, attached algae, and benthic detritus provide about $52.1 \%$ of the total energy of the fish community through the benthic pathway and that terrestrial plants provide $31.4 \%$ of the energy of this community (Xiao 2014). Trophic position estimation using snails to derive an isotope baseline is fairly reasonable as snails integrate both aquatic and terrestrial benthic energy pathways (Lau et al. 2008; Mchugh et al. 2010). Second, we used primary consumer biomass to characterize total resource availability that determines FCL, because they integrate both autochthonous and allochthonous resources, considered the subsidy effect on FCL.

In conclusion, we evaluated the effects of resource availability, ecosystem size, and disturbance on FCL of subtropical rivers and found that resource availability plays a significant role in determining FCL. Increasing the energy supply of a river could lengthen its FCL by supporting a greater biomass, sustaining additional trophic levels, and increasing diversity.

Acknowledgments We would like to thank Prof. Xiaoping $\mathrm{Wu}$ from Nanchang University and Dr. Meng Zhang from Jiangxi Academy of Environmental Sciences for providing useful advice for our experimental design. We also thank the anonymous reviewers for their careful reviews of earlier versions of the manuscript; the comments we received helped 
improve this paper significantly. This study was supported by National Natural Science Foundation of China (Grant Nos. 41301077, 41171030, 31170439, and 31370473).

\section{References}

Barton K (2012) MuMIn: R package for model selection and multi-model inference. R package version 1.15.5. http:// CRAN.R-project.org/package $=$ MuMIn

Burnham KP, Anderson DR (2002) Model selection and multimodel inference: a practical information-theoretic approach, 2nd edn. Springer, New York

Cabana G, Rasmussen JB (1994) Modelling food chain structure and contaminant bioaccumulation using stable nitrogen isotopes. Nature 372:255-257

Calizza E, Costantini ML, Rossi D, Carlino P, Rossi L (2012) Effects of disturbance on an urban river food web. Freshw Biol 57:2613-2628

Carpenter SR, Kitchell JF (1993) The trophic cascade in Lakes. Cambridge University Press, Cambridge

Cohen JE, Newman CM (1991) Community area and food-chain length: theoretical predictions. Am Nat 138:1542-1554

Doi H (2012) Resource productivity and availability impacts for food-chain length. Ecol Res 27:521-527

Doi H, Chang KH, Ando T, Ninomiya I, Imai H, Nakano S (2009) Resource availability and ecosystem size predict food-chain length in pond ecosystems. Oikos 118:138-144

Hoeinghaus DJ, Winemiller KO, Agostinho AA (2008) Hydrogeomorphology and river impoundment affect foodchain length of diverse Neotropical food webs. Oikos 117:984-995

Huang LL, Wu ZQ, Li JH (2013) Fish fauna, biogeography and conservation of freshwater fish in Poyang Lake Basin, China. Environ Biol Fish 96:1229-1243

Jackson AL, Inger R, Parnell AC, Bearhop S (2011) Comparing isotopic niche widths among and within communities: Bayesian analysis of stable isotope Bayesian Ellipses in R. J Anim Ecol 80:595-602

Jacob PZ, Christopher TS, Bruce PF, Irene GE (2015) Macrophyte biomass predicts food chain length in shallow lakes. Ecosphere 6:art5

Jenkins B, Kitching RL, Pimm SL (1992) Productivity, disturbance and food web structure at a local spatial scale in experimental container habitats. Oikos 65:249-255

Jepsen DB, Winemiller KO (2002) Structure of tropical river food webs revealed by stable isotope ratios. Oikos 96:46-55

Lau DCP, Leung KMY, Dudgeon D (2008) What does stable isotope analysis reveal about trophic relationships and the relative importance of allochthonous and autochthonous resources in tropical streams? A synthetic study from Hong Kong. Freshw Biol 54:127-141

Layman CA, Arrington DA, Montana CG, Post DM (2007) Can stable isotope ratios provide for community-wide measures of trophic structure? Ecology 88:42-48

Mchugh PA, Mcintosh AR, Jellyman PG (2010) Dual influences of ecosystem size and disturbance on food chain length in streams. Ecol Lett 13:881-890

Parnell AC, Inger R, Bearhop S, Jackson AL (2008) SIAR: stable isotope analysis in R. http://cran.r-project.org/web/ packages/siar/index.html
Parnell AC, Inger R, Bearhop S, Jackson AL (2010) Source portioning using stable isotopes: coping with too much variation. PLoS ONE 5:e9672

Pauly D, Christensen V, Dalsgaard J, Froese R, Torres F Jr (1998) Fishing down marine food webs. Science 279:860-863

Perkins MJ, McDonald RA, van Veen FJF, Kelly SD, Rees G, Bearhop S (2014) Application of nitrogen and carbon stable isotopes $\left(\delta^{13} \mathrm{C}\right.$ and $\left.\delta^{15} \mathrm{~N}\right)$ to quantify food chain length and trophic structure. PLoS ONE 9:e93281

Pimm SL (1982) Food webs. Chapman and Hall, London

Pimm SL, Kitching RL (1987) The determinants of food chain lengths. Oikos 50:302-307

Pimm SL, Lawton JH (1977) The number of trophic levels in ecological communities. Nature 275:542-544

Post DM (2002a) The long and short of food-chain length. Trends Ecol Evol 17:269-277

Post DM (2002b) Using stable isotopes to estimate trophic position: models, methods, and assumptions. Ecology 83:703-718

Post DM, Takimoto G (2007) Proximate structural mechanisms for variation in food-chain length. Oikos 116:775-782

Post DM, Pace ML, Hairston NG (2000) Ecosystem size determines food-chain length in lakes. Nature 405:1047-1049

R Development Core Team (2010) R: a language and environment for statistical computing. R Foundation for Statistical Computing, Vienna. Available at http://www.R-project.org/

Rybczynski SM, Walters DM, Fritz KM, Johnson BR (2008) Comparing trophic position of stream fishes using stable isotopes and gut contents analysis. Ecol Fresh Fish 17:199-206

Sabo JL, Finlay JC, Post DM (2009) Food chains in freshwaters. Ann N Y Acad Sci 1162:187-220

Sabo JL, Finlay JC, Kennedy T, Post DM (2010) The role of discharge variation in scaling of drainage area and food chain length in rivers. Science 330:965-967

Schoener TW (1989) Food webs from the small to the large: the Robert H. MacArthur award lecture. Ecology 70:1559-1589

Takimoto G, Post DM (2013) Environmental determinants of food-chain length: a meta-analysis. Ecol Res 28:675-681

Takimoto G, Spiller DA, Post DM (2008) Ecosystem size, but not disturbance, determines food-chain length on islands of the Bahamas. Ecology 89:3001-3007

Thompson RM, Townsend CR (2005) Energy availability, spatial heterogeneity and ecosystem size predict food-web structure in streams. Oikos 108:137-148

Thompson RM, Dunne JA, Woodward G (2012) Freshwater food webs: towards a more fundamental understanding of biodiversity and community dynamics. Freshw Biol 57:1329-1341

Vander Zanden MJ, Fetzer WW (2007) Global patterns of aquatic food chain length. Oikos 116:1378-1388

Vander Zanden MJ, Cabana G, Rasmussen JB (1997) Comparing the trophic position of littoral fish estimated using stable nitrogen isotopes $\left(\delta^{15} \mathrm{~N}\right)$ and dietary data. Can J Fish Aquat Sci 54:1142-1158

Vander Zanden MJ, Shuter BJ, Lester N, Rasmussen JB (1999) Patterns of food chain length in Lakes: a stable isotope study. Am Nat 154:406-416 
Walters AW, Post DM (2008) An experimental disturbance alters fish size structure but not food chain length in streams. Ecology 89:3261-3267

Wang SK (1997) The distribution of freshwater fish and the relationship between species diversity and basin characteristics of main rivers in China. Chin Biodivers 5:197-201

Wang YY, Yu XB, Zhang L, Lei GC (2013) Seasonal variability in baseline $\delta^{15} \mathrm{~N}$ and usage as a nutrient indicator in Lake Poyang, China. J Freshw Ecol 28:365-373

Warfe DM, Jardine TD, Pettit NE, Hamilton SK, Pusey BJ, Bunn SE, Davies PM, Douglas MM (2013) Productivity, disturbance and ecosystem size have no influence on food chain length in seasonally connected rivers. PLoS ONE 8:e66240

Xiao XW (2014) Stable Isotope Analysis of Food web structure in Raohe River, Jiangxi Province. Dissertation, University of Chinese Academy of Sciences

Xu J, Wen Z, Ke Z, Zhang M, Guo N, Hansson LA, Xie P (2014) Contrasting energy pathways at the community level as a consequence of regime shifts. Oecologia 175:231-241 